\title{
DESIGNING CULTURAL COMPLEX OF KERMAN WITH AN APPROACH TO HIGHLIGHT FAMES OF KERMAN PROVINCE
}

\author{
Ali Afsharipour \\ Master of Architecture, Rafsanjan Branch, Islamic Azad University, Rafsanjan, Iran \\ Siavash Rashidi-Sharifabad* \\ Assistant Professor, Faculty Member of Architecture Group, Islamic Azad University \\ Shahr-e Babak, Iran \\ *Corresponding Author \\ s.rashidi@srbiau.ac.ir
}

\begin{abstract}
Cultural complexes as valuable cultural heritage of the ancestors can be one of the main causes of urban identity to be useful by providing their historic, cultural and social attractions in recognition of values to the people and even tourists. In this context, concerning cultural monuments has had great importance because, they have a unique role in the creation of high status for the promotion of culture, science and knowledge in youths through providing a place for young people to gather and research and exchange of cultural and artistic and literary information; a place where can be a kind of manifestation of culture and art of the past and its current evolution besides the leisure and entertainment at different ages. So, this research got help of librarian research method in order to answer how to reach their target with a descriptive way to collect data by analyzing the content of existing texts, resources, library documents (articles, essays and books). The analysis method of this data was qualitative which sorted and selected the concepts and indexed collected data with an interpretative approach. Finally, as s conclusion and summary; this study had an approach to learn more about fames and how they interact with the culture as well as compliance of their achievements with today's knowledge that has had a significant impact on designing cultural complex as an attractive place for visitors and also, confirms the need for extensive studies in this regard.
\end{abstract}

Keywords: Designing, Culture, Cultural Complex, Highlighting, Fames.

\section{INTRODUCTION}

Cultural complexes as valuable cultural heritage of the ancestors can be one of the main causes of urban identity to be useful by providing their historic, cultural and social attractions in recognition of values to the people and even tourists. Historical and cultural sites of every society reflect the norms and values of the community and social and cultural identity includes the origin of any community somehow (Oghli, 2014). So that it clearly shows who and what is each society. A cultural complex can be considered as a place for young people to gather and research and exchange of cultural and artistic and literary information and in general, as a place with high status for the promotion of culture, science and knowledge in youths (Greuther, 2011). A place where can be a kind of manifestation of culture and art of the past and its current evolution besides the leisure and entertainment at different ages. Fames are people who have been influential in promoting the name of Kerman as time passed and one of the objectives that would be achieved is to create a complete database of the scholars and scientists of the Kerman province to introduce and identify them to people more and more and one of the options that will cause historical record and maintenance of these characters is to get their lives among the people and in fact, objectifying them for those who may not have an incentive to study and see the history (Daneshpour \& Charkhchian, 2007). This approach can also be important in this respect that highlighting certain views of their times and period in the life of these fames interacting with the current time to remind and highlight what is forgotten 
now in the relations and the modern life (Asgari-kohan, 2015). Another option is to illustrate different aspects of their biography and especially their efforts and during the life in the various scientific, cultural, literary, social and political areas as well as effective steps in this regard to serve humanity and promoting people and further progress and excellence of the ancient country, Iran, because the history can inform anyone from the bittersweet story and goodness of the past nations (Daneshvar, 2009). Due to the fact that in most places in the world are in the thoughts of introducing their past by highlighting the fames, thus, this issue needs more attention in the index scale. The present study emphasized more on the fames of Kerman province and sought to design a cultural complex on the basis of introducing these fames and their works (Abolqasemi, 2012). The aim of this proposed method is to present a suitable and standard model for architects and designers to be able to design a cultural complex by which that takes step towards highlighting fames. This project is the design of a complex including educational, cultural, artistic, sporting, recreational, etc. areas to respond three important things: direct instruction, indirect instruction and opportunity for training skills that promotes the cultural level of society. In addition, attracting various talents, tastes and opinions in a complex besides a proper management will have the best results of confluence of thoughts (Najmi, 2011). Hence, the purpose of this study was to design the cultural complex of Kerman with an approach of highlighting fames of Kerman province.

\section{METHODOLOGY}

The research method was descriptive survey. So, this research got help of librarian research method by the purpose of highlighting the fames and recognition of effective factors on the use of desirable space in order to evaluate cultural and artistic issues and pleasant leisure time of citizens associated with upbringing individual creativities as well as answer to the sense of spatial identity and sense of belonging to the environment with a descriptive way to collect data by analyzing the content of specialized documents and books, texts related to the fames, internet portal and taking pictures and notes from internal and external scientific articles. The analysis method of this data was qualitative which sorted and selected the concepts and indexed collected data with an interpretative approach. The data was collected by referring to the following competent authorities.

- $\quad$ Reference to the books and journals in the field of culture.

- Reference to the Kerman survey center and interviews with people.

- Gaining information from cultural centers.

- Gaining information and statistics about the local climate, weather conditions for the preparation of the framework and conditions and the design of buildings and facilities.

- Gaining technical information on standards, regulations of design and etc. to adapt designing with the demands of users.

- $\quad$ Collecting data about the topographic map and ...

- Visiting the ground and site of plan.

- $\quad$ Recording observations and impressions.

- Providing photographs of natural and geographical conditions and regional physical appearance.

- $\quad$ Checking the status of existing infrastructure in the region.

- Study of proposals for the cultural complex.

\section{RESULTS}

\section{AREA AND DIMENSIONS}

Land area was about 33376 square meters. Dimensions of the site were about $205 \times 165$.

\section{SITE'S LIGHTING}

Direct sunlight in hot and arid regions has been severe and this intensity will be even increased with the added radiation reflected from the ground. The sunlight warms the earth's surface to $70{ }^{\circ} \mathrm{C}$ during the day in summer. In southern parts of Iran including Kerman, angle of radiation is more vertical than the rest (Basically, as going closer to the equator, radiation of sunshine will close to the 
perpendicular). This issue associated with low humidity in environment and low water vapor in the air adsorbs radiation energy to the surface with a very high percentage (Figure 1).

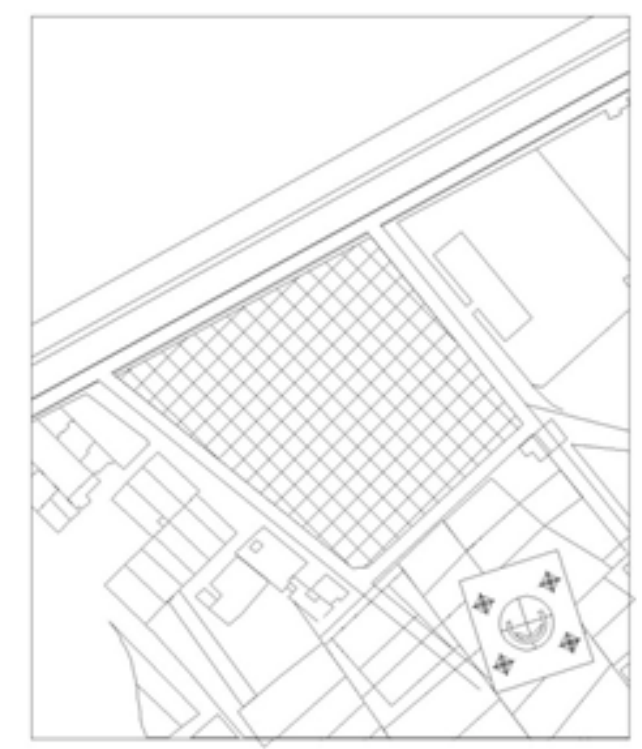

Figure 1. Analysis of the site's lighting direction

\section{SURROUNDINGS}

\section{1) NEIGHBORHOODS}

1. From the East: Iran Khodro representation and Vesal hall
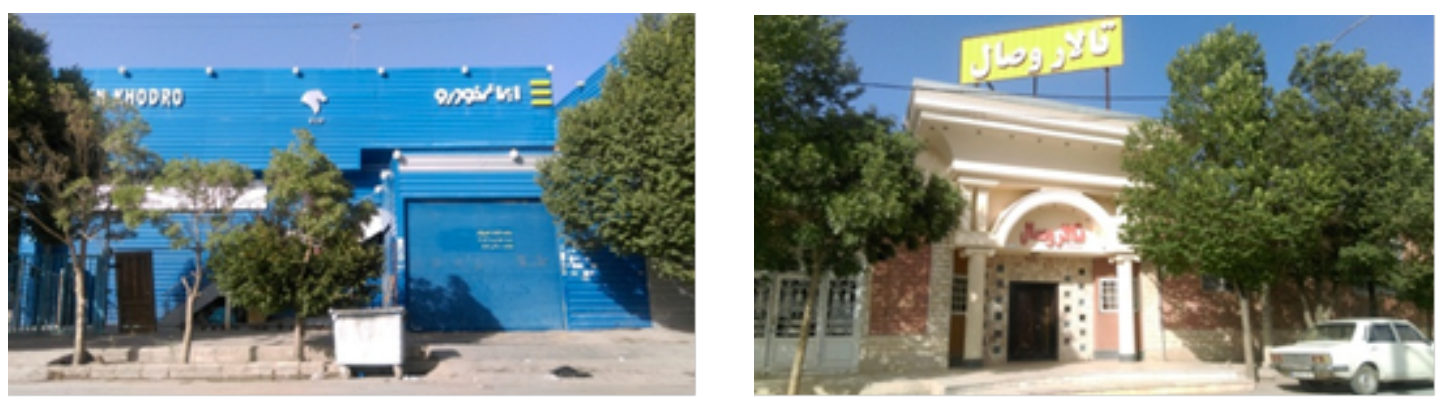

Figure 2. Neighborhood of East of the site

2. From the West: residential houses

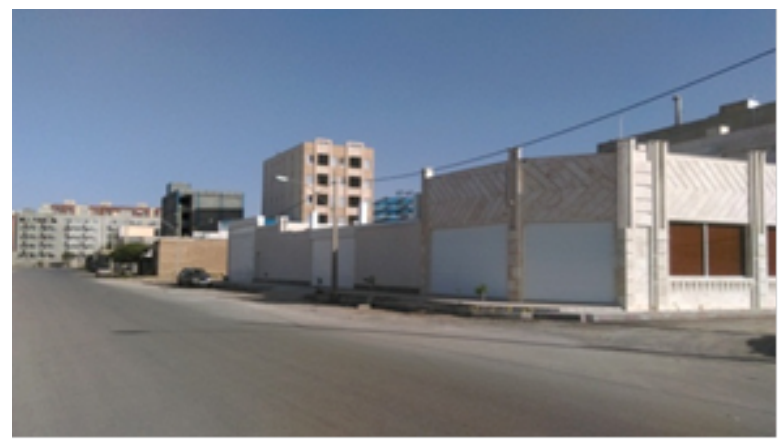

Figure 3. Neighborhood of West of the site 
3. From the North: the Islamic Republic of Iran boulevard

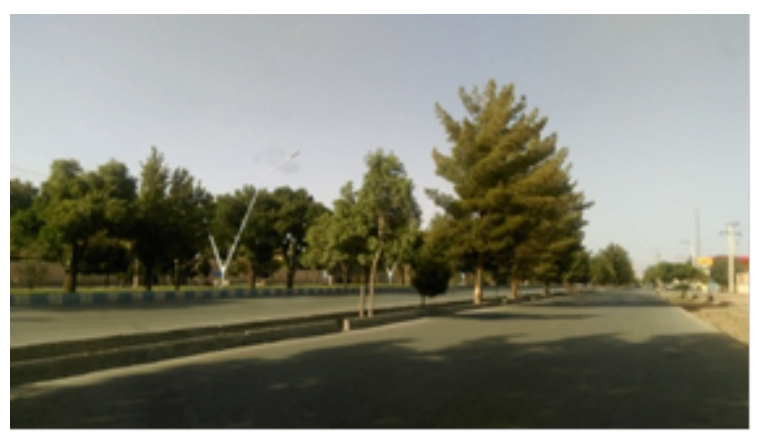

Figure 4. Neighborhood of North of the site

4. From the South: residential houses

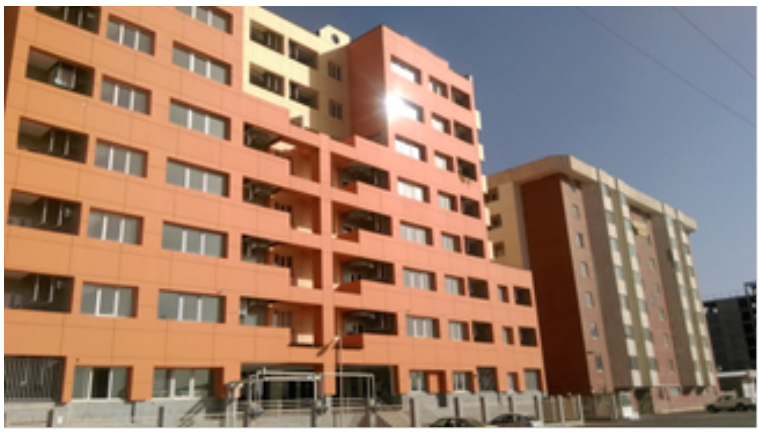

Figure 5. Neighborhood of South of the site

\section{ACCESS}

Due to the place of land in the vicinity of the Islamic Republic of Iran Boulevard, this communication path would be introduced as the most important access network to the site, so that, connecting of the rest of complex with the city can be possible via this boulevard.

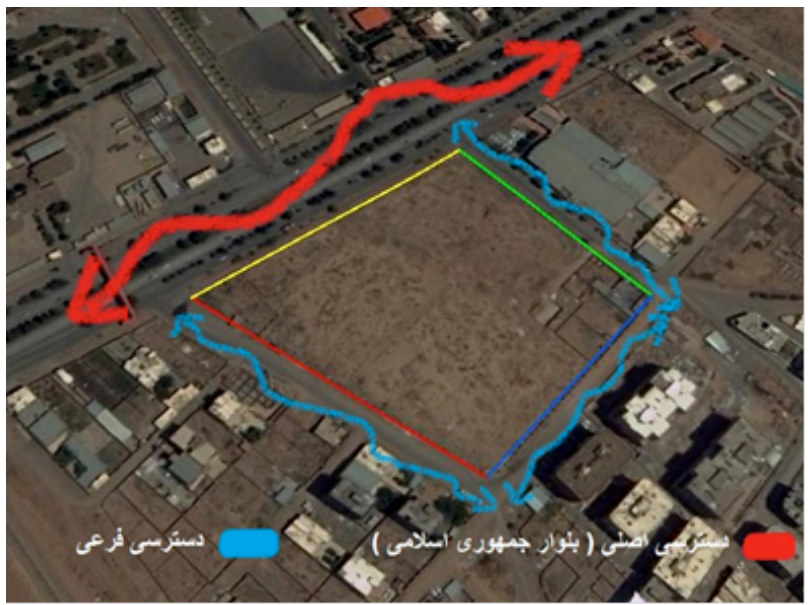

Figure 6. Access of the site

\section{PROVIDING RELEVANT STANDARDS AND GUIDELINES}

Considering the impact of each of the climate factors on the architecture and other structural properties can cause to determine the most appropriate type of design, materials, construction type, body type and direction of establishing buildings according to the respective climates. 


\section{CHOOSING BUILDING'S FORM WITH REGARD TO THE CLIMATE}

Cold weather usually causes compression in the building and high intensity sunlight leads the building to stretch along with the eastern-western axis. In other words, in hot and dry areas, high-intensity radiation on the eastern-western side cause the building to be stretched in form. This form is inside the building in terms of air conduction and convenience for reducing indoor air humidity.

\section{CHOOSING APPROPRIATE MATERIALS}

Due to the fact that temperature swings much during night and day in hot and dry areas, the most appropriate type of construction materials are materials with high thermal resistance and higher thermal capacity. The bright color choice for exterior building materials, of course, can also be considered to absorb less solar thermal energy.

\section{DIRECTION OF ESTABLISHMENT}

According to studies carried out, the best proposed angle was in five degree to the East from the South and with regards to the resulting curve, the length of the vector represents difference of about 5 degrees of southeast to 48 degrees to the West.

\section{WIND}

Situations where the proper winds blow in the effective range of the building, while annoying winds are placed in the ineffective area; therefore, the appropriate range of involvement can be introduced close to 48 degrees of southeast to 41 degrees o southwest.

\section{CONDITIONING}

In hot and arid regions, meeting the principles such as effective and continuous ventilation, protecting walls and windows against the sunlight and avoidance of overheating of indoor air during the day shall cause minimization of air temperature. However, due to the extreme heat in some months, it can be found out that creating comfort zones in critical condition is not possible just with air conditioning and using materials because of dry weather in these areas, so, the air conditioner devices should be used to control indoor air.

\section{SERVICE}

Requirements:

-

Predicti

ons are needed in order to effective cleaning and maintenance without disturbing visitors and staff.

- Transportation: carts for service.

- Control of systems of determining the status of each floor.

\section{DOORS}

Doors should become opened without any obstacles (locked doors should have release system in times of turbulence), sliding doors are not acceptable, but presence of two escape doors installed in their vicinity.

Other predictions:

- $\quad$ Correct marking through independent color and brightness

- $\quad$ Exit doors with auto closing system

- Warning system

- $\quad$ Emergency lighting 


\section{MATERIAL SAFETY AND PROTECTION}

Security is a considerable point for visitors in the non-acquainted environments. The security system is required for the control and eventual loss or damage to property.

\section{SECURITY SYSTEMS:}

1. Warning and detectors devices

2. Closed-Circuit systems

\section{PROTECTION AGAINST FIRE:}

Requirements relating to fire at such centers are necessary because:

- The high number of people is there in different locations who are not familiar with warning systems (employees, visitors).

- $\quad$ Accumulation of visitors in the gallery or amphitheater

- High density of furniture and their sensitivity in terms of historic and material qualifications value

The main items to protect against fire are:

- $\quad$ Structural protection consists of using anti-fire building elements and substances and restrictions on the use of flammable materials that carry a lot of fire.

- $\quad$ Active protection includes fire alarm systems (heat, smoke, carbon dioxide, warning devices of various types of fire extinguishers).

\section{WAYS TO ESCAPE}

At the time of the fire, short path for the exit to a safe place is very important for residents. The escape staircases in multi-floor buildings are essential.

\section{CLOSED-CIRCUIT TELEVISION SYSTEMS}

These systems are widely used to view the movements. The cameras should be installed in such a way that can be secured from the direct exposure at light reflection and polished surfaces and must be hidden.

\section{PHYSICAL PLANS (SKELETAL PLANS)}

A cultural complex has diverse areas, spaces that make different activities possible; activities such as studying in library, theater and conferences in the amphitheater and exercise in outdoor sport lands, dining in restaurants, etc. Each of them composed of different sectors and parts and has their own rules and regulations and the absence of one part in one of the buildings in the complex can damage all. Meeting standards and physical regulations of different spaces and parts are as the priority of the project in the process of designing this cultural complex and design is done based on the principles of architecture.

\section{GOALS OF PHYSICAL PLANNING}

- Economic building construction and the savings still to reduce the costs

- Foresight and taking into account the developments and changes in the description of tasks and volume of clients

- Privacy protection

- Appropriate appearance of government buildings in the city and providing dignity required for that 
- Proper quality of spaces in providing facilities for staff and clients

- Logical technical proportions in the establishment of spaces in classes

\section{CLASSIFICATION}

\subsection{ADMINISTRATIVE DISTRICT}

The administrative and management district is organizer, planner, founder and connector between different parts of the complex. It is considered as the core of the complex. This section is made up of different parts; each is described as follows (Moradian, 2007).

\section{- MANAGEMENT OR THE HEAD:}

The manager is responsible for the supervision or control of affairs in organizations and companies. Manger determines the general policy of the company and how to do services with cooperation of deputies and etc.

Manager's room requires related utilities such as table since it is the place of working; moreover, it is a place for reception and discussion at the certain level. Hence, it is a relatively wide place and the furniture used there is proportional to its certain condition. It contains two parts of working part and reception part and in most cases, a place for administrative and managerial meetings (Moradian, 2007).

\section{- DEPUTY:}

He is responsible for collaboration and consultation as an executive arm for the manager that is as his successor in a closer monitoring of tasks and direct communication with executive staff. The deputy also meets and discusses with clients, so his room will also have a reception except his office. Of course, it is possible that management of an administrative organization have some deputy in different executive areas (Moradian, 2007).

\section{- EXPERT:}

Experts are responsible for technical deal with their clients and conduct the affairs with details and fully operational (Moradian, 2007).

\section{- SECRETARY:}

Secretaries are responsible for doing service affaires of management section (managers and deputy) and coordinating and tracking their actions and, in some cases, typing correspondence, archiving documents, coordinating managers' and assistants' meetings and things like this. Thus, with regards to the diversity of duties, secretary's rooms are considered as an input and division space for management sector (Moradian, 2007).

\section{- SERVICE ROOMS:}

These rooms are for work and establishment of service staff, including debt collectors, butlers, chambermaid, etc. Conventional administrative appliances such as tables and chairs are placed in some of the rooms, and in others, there are special requirements (Moradian, 2007).

\section{- PUBLIC RELATIONS:}

Coordination of all parts in the complex and preparation of programs in terms of internal and external relations shall be done by this section which works directly under the supervision of deputy of the complex. This section requires one person as an internal public relations expert and one as an external public relations expert (Moradian, 2007). 


\section{- SECURITY:}

Establishment of discipline and security and control of affaires take place in a relatively closed set. Closed circuit television systems are used in each part in addition to physical presence of the guardians in different parts of the complex; and this is why this section requires video and photographic equipment (Table 1) (Moradian, 2007).

Table 1. Physical planning of administrative district

\begin{tabular}{|c|c|c|c|c|}
\hline Row & Space description & Number & $\begin{array}{c}\text { Unit } \\
\text { substructure }\end{array}$ & $\begin{array}{c}\text { Total } \\
\text { substructure }\end{array}$ \\
\hline 1 & Management & 1 & 79 & 79 \\
\hline 2 & Manager's secretary & 1 & 26 & 26 \\
\hline 3 & Meeting room & 1 & 164 & 164 \\
\hline 4 & Archive & 1 & 179 & 179 \\
\hline 5 & Security & 1 & 41 & 41 \\
\hline 6 & Closed circuit cameras' room & 1 & 29 & 29 \\
\hline 7 & Business & 1 & 23 & 23 \\
\hline 8 & Financial expert & 1 & 44 & 44 \\
\hline 9 & Deputy's secretary & 1 & 28 & 28 \\
\hline 10 & Deputy & 1 & 60 & 60 \\
\hline 11 & Public relations & 1 & 60 & 60 \\
\hline 12 & Pantry & 1 & 62 & 62 \\
\hline 13 & Toilet & 4 & 30 & 30 \\
\hline 14 & Registration & 1 & 39 & 39 \\
\hline \multirow[t]{2}{*}{15} & Council & 1 & 37 & 37 \\
\hline & Total & & & 901 \\
\hline
\end{tabular}

\subsection{DEMONSTRATIVE DISTRICT}

\section{- TEMPORARY EXHIBITION:}

The performances, exhibitions and sale of achievements resulted from the actions of the complex are considered as the issues in that complex, so that, the real value has been represented with all the delicacy and precision concerned in the production.

\section{- AMPHITHEATER:}

Entrance: It shall be such that preventing the concentration of people in the back of the door and people can easily buy a ticket and enter the hall (Moradian, 2007). 
Foyer (lobby): It is located after the entrance. Another element in the hall is buffet. The other space in the hall is toilet, and since it is a grade 3 space, it should not be located in a full view. It is better to be somewhere that is easily accessible, because it is as the service spaces (Moradian, 2007).

Venues: Totally, maximum capacity of the audience is dependent to the selected shape and audiovisual limitations and their index is the kind of program production. Other factors include levels, line of sight, acoustic, traffic congestion and the size and shape of the stage (Moradian, 2007).

Processing room for artisans: This is one of the main and applicable spaces in hall. It should be noted in the design of this space that this space is considered as a private space and must maintain all its privacy, especially for women. This space should be in direct relation with the scene and free of noise with enough light (Moradian, 2007).

\section{- GALLERY:}

Galleries are proposed as one of the essentials in cultural centers. Gallery should be a space with the following features:

- Show of artworks with the proper conditions in terms of light, space and...

- Protection of the artworks from moisture, damage, fire, dust, light, sunlight and...

Todays' tendency in designing the galleries has more emphasis on the design of integrated spaces that can be made up with movable dividing walls and lightweight components. How to provide light in the gallery is among the factors of determining the design. The light can be provided natural and artificial (Table 2).

Table 2. Physical planning of demonstrative district

\begin{tabular}{|c|c|c|c|c|}
\hline Row & Space description & Number & $\begin{array}{c}\text { Unit } \\
\text { substructure }\end{array}$ & $\begin{array}{c}\text { Total } \\
\text { substructure }\end{array}$ \\
\hline \multicolumn{5}{|c|}{ Temporary exhibition } \\
\hline 1 & Hall & 1 & 514 & 514 \\
\hline 2 & Supervision & 1 & 35 & 35 \\
\hline 3 & Sale stall & 1 & 32 & 32 \\
\hline \multicolumn{5}{|c|}{ Fames' hall } \\
\hline 1 & Statue hall & 1 & 958 & 958 \\
\hline 2 & Conversation hall & 1 & 1408 & 1408 \\
\hline \multicolumn{5}{|c|}{ Amphitheater } \\
\hline 1 & Main hall & 1 & 1021 & 1021 \\
\hline 2 & Ticket sale & 1 & 5 & 5 \\
\hline 3 & Ticket confirmation & 1 & 5 & 5 \\
\hline 4 & Processing room & 2 & 28 & 56 \\
\hline 5 & Toilet & 4 & 7 & 14 \\
\hline
\end{tabular}


The Turkish Online Journal of Design, Art and Communication - TOJDAC July 2016 Special Edition

\begin{tabular}{ccccc}
\hline \multicolumn{5}{c}{ Gallery } \\
\hline 1 & Hall & 1 & 743 & 743 \\
\hline 2 & Supervision & 1 & 52 & 52 \\
\hline 3 & Sale stall & 1 & 25 & 25 \\
\hline 4 & Warehouse & 1 & 62 & 62 \\
\hline 5 & Toilet & 6 & 22 & 22 \\
\hline & Total & & & 4952 \\
\hline
\end{tabular}

\subsection{INFORMATIVE DISTRICT}

Activities of this section can be considered in the two theoretical and practical parts. The theory consists of classes with the intention of promoting and improving the level of knowledge in clients. In the practical part, clients will produce cultural products directly in instructive workshops.

\section{- AUDIOVISUAL:}

In recent years, new equipment has created a situation that information is not transmitted only through reading the story. The audiovisual part has proportionally important role in serving, collecting and storing obtained information. This complex offers a way for the person who is seeking information, through which he can find the required information that is stored in one of the audio-visual sources. Library and audiovisual section can perform as complementary for each other (Table 3) (Moradian, 2007).

\section{- COMPUTER CENTER:}

The proposed complex can be implemented as follows:

1. The main computer system with large memory

2. LAN network

3. The number of computers for clients

4. Computer publishing system

5. The computer graphics system for promotions (Moradian, 2007).

Table 3. Physical planning of informative district

\begin{tabular}{ccccc}
\hline Row & Space description & Number & $\begin{array}{c}\text { Unit } \\
\text { substructure }\end{array}$ & $\begin{array}{c}\text { Total } \\
\text { substructure }\end{array}$ \\
\hline 1 & Supervision & 1 & 62 & 62 \\
\hline 2 & Theoretical class & 5 & 94 & 470 \\
\hline 3 & Instructive workshop & 3 & 331 & 331 \\
\hline
\end{tabular}


The Turkish Online Journal of Design, Art and Communication - TOJDAC July 2016 Special Edition

\begin{tabular}{ccccc}
\hline 4 & Computer system & 1 & 87 & 87 \\
\hline 5 & Copy room & 1 & 18 & 18 \\
\hline 6 & Audiovisual & 1 & 61 & 61 \\
\hline 7 & Toilet & 6 & 22 & 22 \\
\hline 8 & Warehouse & 1 & 62 & 62 \\
\hline 9 & Pantry & 1 & 20 & 20 \\
\hline 10 & Management & 1 & 20 & 20 \\
\hline 11 & Faculty break room & 1 & 100 & 100 \\
\hline & Total & & & 1253 \\
\hline
\end{tabular}

\subsection{RESEARCH DISTRICT}

\section{- LIBRARY:}

\section{THE LIBRARY SPACES:}

Factors influencing the allocation of the library spaces include the volume of materials and texts, especially books and the level of space that will be occupied in the library as well as the population that is determined through the library's circulation in a year (Moradian, 2007).

\section{DIMENSIONS AND STANDARDS OF THE COUNTER AND CARD CABINET:}

Maximum index shelf's height is usually equal to the height of six drawers each filled with about a hundred cards. Index is usually located in direct contact with the circulation and reference's desks and often in the vicinity of them; there is a set of reference books or public use cases. Therefore, the location of index is usually in an open space close to the entrance that composed of rows of index shelves and counters for check and seeks in the drawers (Moradian, 2007).

\section{STANDARDS OF SHELVES DIMENSIONS AND DEPTH:}

In most libraries, $90 \%$ of books have at least less than $230 \mathrm{~mm}$ width and a shelf with 200 to $230 \mathrm{~mm}$ depth can indeed be assumed as standard. More savings in space comes into action in case of using double-sided shelves with a depth of $450 \mathrm{~mm}$ (Moradian, 2007).

The shelf with $490 \mathrm{~mm}$ depth can help for keeping books with slightly larger dimensions. As a rule of thumb, $80 \%$ of shelves in a library have $200 \mathrm{~mm}$ depth, $15 \%$ of them are $250 \mathrm{~mm}$ and the rest of $5 \%$ have $300 \mathrm{~mm}$ depth (Moradian, 2007).

\section{STANDARD OF DESKS:}

Desks are among the most important means of study spaces.

Standards of desks for different tables are as follows:

1-person table: the acceptable figure for this table is $600 \times 900 \mathrm{~mm}$. Sometimes, this figure will increase up to a meter for more convenience. Although more attraction, they occupy a large space (Moradian, 2007). 
Long tables: Long table can accommodate 4 to 12 people. 4-person tables prevent congestion and at the same time, their placement is attractive and flexible. They should not be less than $1200 \mathrm{~mm}$ width. Sidelong space among the readers will also need to be at least $900 \mathrm{~mm}$. the distance between the parallel tables are predicted to be at least $1800 \mathrm{~mm}$. At the same time, it should not be considered a place to sit at the end of this table (Moradian, 2007).

Lighting: The lighting should create a comfortable space for study, causing no fatigue and daze, do not increase the amount of heat and add beauty to the building. To meet the foregoing, there are two types of light: 1) artificial light; 2) natural light.

Both natural light and roof artificial light are used for the project (Moradian, 2007).

Acoustic: There is no certain standard for acoustic in a library, but in most cases, the limit of internal noise level is determined as 50 decibels ( $\mathrm{Db}$ ) (Moradian, 2007).

Air conditioning: In order to create the best conditions for storage of material, space must be free of any dust, including gas, liquid and acid with controlled temperature and humidity; such a situation is possible only with installation of a full air conditioning system (Table 4) (Moradian, 2007).

Table 4. Physical planning of research district

\begin{tabular}{ccccc}
\hline Row & Space description & Number & $\begin{array}{c}\text { Unit } \\
\text { substructure }\end{array}$ & $\begin{array}{c}\text { Total } \\
\text { substructure }\end{array}$ \\
\hline & & Library & & \\
\hline 1 & Studying hall & 2 & 487 & 487 \\
\hline 2 & Reservoir & 2 & 344 & 344 \\
\hline 3 & Book loan & 1 & 36 & 36 \\
\hline 4 & Card confirmation & 1 & 23 & 23 \\
\hline 5 & Card cabinet & 1 & 6 & 16 \\
\hline 6 & Journals and reviews & 1 & 16 & 45 \\
\hline 7 & Supervision & 1 & 45 & 86 \\
\hline 8 & Type and copy & 1 & 86 & 22 \\
\hline 9 & Toilet & 6 & 22 & 1065 \\
\hline & Total & & & \\
\hline
\end{tabular}

\subsection{WELFARE DISTRICT}

\section{- PRAYER ROOM:}

This space will be standardizing based on the number of users. It does not contain specific restrictions in terms of lighting and materials. It is only better to use light and gentle colors and forms used for more sense of calm that is the essence of prayer. Prayer space itself should be divided into two parts for men and women. This separation may be through partitions or curtains to make an integrated space when necessary (Moradian, 2007). 


\section{- TOILET:}

\section{STANDARDS:}

- If ventilation occurs through windows and only in one side, an area of about 170 square centimeters is needed. In the case of space limitations, this is an area of about 100 square centimeters.

- Floors should not be slippery and should be resistant against the water and easy to clean, it should also be seamless floor and washable.

- Walls must be at least as high as 2 meters with washable tiles.

- Suitable temperature for toilet is $21^{\circ} \mathrm{C}$.

- At least one mirror should be installed for each toilet.

- Minimum height of each toilet with four WC or less can be 2.2 meters.

- Minimum width of each toilet should be more than $110 \mathrm{~cm}$.

- Minimum length of each toilet should be more than $110 \mathrm{~cm}$.

- The distance between centers of two toilets should be $60 \mathrm{~cm}$.

- The distance of toilet from the walls should be $45 \mathrm{~cm}$ (Moradian, 2007).

- RESTAURANT:

Restaurant spaces can be separated into three parts:

- Spaces for preparation of foods

- Spaces for providing foods

- Spaces for services

The kitchen is better to locate in the level of dining hall, and a separate access to the kitchen must be predicted for the transfer and handling of food.

\section{- COFFEE SHOP:}

Coffee shops need spaces including:

- Sitting area

- Space for storage, preparation and serving

\section{- WAREHOUSE:}

The space on lower floor in the building has been used as a warehouse to avoid problems caused by the pressure and burden.

\section{- INSTALLATION:}

Installation location should be designed in such a way with easily access to it by mounted and dismounted and away from areas that need peace and quiet (Table 5).

Table 5. Physical planning of welfare district 
The Turkish Online Journal of Design, Art and Communication - TOJDAC July 2016 Special Edition

\begin{tabular}{|c|c|c|c|c|}
\hline Row & Space description & Number & Unit substructure & $\begin{array}{c}\text { Total } \\
\text { substructure }\end{array}$ \\
\hline
\end{tabular}

\begin{tabular}{|c|c|c|c|c|}
\hline \multicolumn{5}{|c|}{ Restaurant } \\
\hline 1 & Dining hall & 2 & 759 & 759 \\
\hline 2 & Foods' serve & 2 & 48 & 48 \\
\hline 3 & Kitchen & 1 & 111 & 111 \\
\hline 4 & Washing room & 1 & 27 & 27 \\
\hline 5 & Toilet & 4 & 31 & 31 \\
\hline 6 & Locker room & 1 & 17 & 17 \\
\hline 7 & Dry warehouse & 1 & 19 & 19 \\
\hline 8 & Wet warehouse & 1 & 25 & 25 \\
\hline 9 & Refrigerator & 1 & 32 & 32 \\
\hline 10 & Dishes' warehouse & 1 & 54 & 54 \\
\hline 11 & Coffee shop & 1 & 114 & 114 \\
\hline \multicolumn{5}{|c|}{ Services } \\
\hline 1 & Security & 1 & 42 & 42 \\
\hline 2 & Information & 1 & 27 & 27 \\
\hline 3 & Prayer room & 2 & 116 & 116 \\
\hline 4 & Toilet & 10 & 81 & 81 \\
\hline 5 & Installation & 1 & 245 & 245 \\
\hline 6 & Warehouse & 1 & 100 & 100 \\
\hline 7 & Janitorial & 1 & 158 & 158 \\
\hline & Total & & & 2006 \\
\hline
\end{tabular}

\subsection{TOTAL INDOOR SPACE}

According to the provided physical planning, summing up the indoor spaces is as follows (Table 6):

Table 6. Total indoor spaces

\begin{tabular}{ccc}
\hline Row & Space description & Total substructure \\
\hline 1 & Administrative district & 901 \\
\hline
\end{tabular}


The Turkish Online Journal of Design, Art and Communication - TOJDAC July 2016 Special Edition

\begin{tabular}{ccc}
\hline 2 & Demonstrative district & 4952 \\
\hline 3 & Informative district & 1253 \\
\hline 4 & Research district & 1065 \\
\hline 5 & Welfare district & 2006 \\
\hline 6 & $35 \%$ circulation & 5124 \\
\hline & Total & 15301 \\
\hline
\end{tabular}

\subsection{TOTAL SITE SPACES}

Overall space of the site is offered in Table 7.

Table 7. Total site spaces

\begin{tabular}{ccccc}
\hline Row & Space description & Number & Unit substructure & $\begin{array}{c}\text { Total } \\
\text { substructure }\end{array}$ \\
\hline 1 & Parking & 60 & 15 & 900 \\
\hline 2 & Exhibition & 1 & 850 & 850 \\
\hline 3 & Sport land & 2 & 600 & 1200 \\
\hline 4 & Conversation park & 3 & 1800 & 1800 \\
\hline 5 & Amphitheater & 1 & 800 & 800 \\
\hline 6 & Security & 2 & 75 & 75 \\
\hline 7 & Communicational spaces & & 19259 & 19250 \\
\hline & Total & & & 24875 \\
\hline
\end{tabular}

\section{CONCLUSION}

Fames in each community are one of the most important environmental factors affecting design and construction of multiple architectural species and one of the architectural features is that it figures in the context of their environment under the affection of all spiritual and material features of the environment. So apart from those mentioned previously, a number of Iranian architectural elements (that has been represented in the culture and climate in a special type) is evident in the design of Kerman cultural complex that follows the principles of architecture like purposefulness, geometry, light, transparency of spaces, popularity, introspection, simplicity and so on. Among the elements Submit Date: 01.05.2016, Acceptance Date: 20.06.2016, DOI NO: 10.7456/1060JSE/060 
considered in the design of this complex, it can be noted in Bazzar of Chahar Suq which plays a role as a distribution space and also, it is attempted to use Rasteh Bazaar with its roof lightings that can be seen in the final volume. In designing Hall of Fame, it was tried to get an idea from cultural monuments already in Kerman for more effectiveness on visitors and as a result, a confirming freezer (يخدان مويدى) was considered for this important that is now the venue for various cultural activities. Other influential factors in the design of this complex can be the Republic Boulevard that has been effective on the rotating volume and the formation of lines. Using these cases resulted in drawing a form that evokes the rich culture of this country for visitors and yet the lines and forms that are intended to grow and flourish that was approved as an appropriate method and the final design was achieved after necessary efforts based on the results of studies conducted on the subject matter. The study has come to a conclusion that traditional and ruling architecture of Iran is full of mystery and secret and these parables still have the potential that todays' architecture can provide a new form of expression by these ancient concepts, and this means that every generation must redefine the old symbol that has come from the generation before him, and explain old concepts in terms of his age again; because the architecture is the expression of the space, so that the observer make a certain experience of space in relation to previous and future experiences. This is the same principle that this project wants to make it modern to highlight the fames with the idea of ancient concepts, and to consider the tastes and needs of the today's audience in representing these concepts more than anything else. In this process, the cultural complex was remembered as a platform for highlighting fames to make this generation familiar with its own identity leading to the prosperity and success through introduction of fames in this land.

\section{REFERENCES}

Abolqasemi MR, 2012. Aesthetic principles. Tehran University.

Asgari-kohan R, 2015. The National Center for Kerman carpet. Master's thesis, architecture, Azad University of Kerman.

Daneshpour AH, Charkhchian M, 2007. Public spaces and factors affecting communal life. BaghNazar journal. 7: 19-28.

Daneshvar M, 2009. Brilliant Faces of Kerman. Kerman survey center. First printing.

Greuther JK, 2011. Aesthetic in architecture. Translated by Doctor Jahanshah Pakzad and Abdul-Reza Homayoun. Publication of Shahid Beheshti University of Tehran. $7^{\text {th }}$ printing.

Moradian M, 2007. International Trade Centre of Carpet. Master's thesis, architecture, Azad University of Kerman

Najmi S, 2011. Historiography in Kerman. Shahid Bahonar University of Kerman. First printing. Oghli HA, 2014. Cultural Complex. M.Sc thesis, architecture, Azad University of Rafsanjan. 